\title{
Severe Mitral Regurgitation Secondary to Atresia of the Posterior Mitral Valve Leaflet in the Adult: Is Repair Always Best Practice?
}

\author{
Vijay Joshi $^{1}$ Kaye Laurie ${ }^{1}$ Julian Skoyles ${ }^{2}$ David Richens ${ }^{1}$ \\ ${ }^{1}$ Department of Cardiac Surgery, Nottingham City Hospital, \\ Nottingham, United Kingdom \\ 2 Department of Cardiac Anaesthesia, Nottingham City Hospital, \\ Nottingham, United Kingdom \\ Address for correspondence Kaye Laurie, Department of Cardiac
Surgery, Nottingham City Hospital, Hucknall Rd, Nottingham NG5
1PB, United Kingdom (e-mail: kayeprosser@nhs.net).
}

Thorac Cardiovasc Surg Rep 2015;4:34-36.

\begin{abstract}
Keywords

- cardiac surgery

- mitral valve repair

- heart valve disease

We describe a case of a 66-year-old woman with severe mitral regurgitation secondary to posterior leaflet atresia of the mitral valve. Perioperative transesophageal echocardiography suggested the possibility of an absent posterior leaflet with complete prolapse of the anterior leaflet. We questioned the functional outcome if repair was attempted; therefore, mitral valve replacement was performed. We present a case outlining the successful management of this rare condition in an adult as well as a review of current literature.
\end{abstract}

\section{Introduction}

Congenital defects resulting in mitral insufficiency presenting in late adulthood are rare. ${ }^{1}$ They can be caused by underdevelopment of any of the four components of the mitral valvular complex including the annulus, leaflets, chordae tendineae, and papillary muscles. ${ }^{2}$ We report a case of mitral regurgitation that developed as a consequence of posterior leaflet atresia.

\section{Case History}

A 66-year-old woman, with a known heart murmur since childhood, presented with a history of progressive shortness of breath over a 6-year period. She had been followed up as having mitral valve prolapse and had been in atrial fibrillation for the past 6 years. At the time of referral her degree of heart failure was New York Heart Association (NYHA) Class III. Her medical history included rheumatic joint disease and smoking. Physical examination revealed a loud pansystolic murmur over the left sternal border radiating to the axilla and atrial fibrillation but there were no other physical signs.
Preoperative transthoracic echocardiography revealed thickened anterior leaflet of the mitral valve and complete prolapse of the anterior leaflet (A1, A2, and A3 scallops), resulting in a posteriorly directed eccentric jet of severe mitral regurgitation hugging the left atrial wall. Additional findings included a moderately dilated left atrium and borderline dilated left ventricular cavity with preserved function. There were no other significant valve abnormalities present. Cardiac catheterization showed no evidence of coronary artery disease. Blood tests were unremarkable.

A decision to proceed with mitral valve repair or possible replacement was made and the patient was listed for elective surgery. A perioperative transesophageal echocardiogram revealed similar findings to her preoperative scan but there was a question as to whether the posterior leaflet was absent ( - Fig. 1). During the operation, there was a congenital atresia of the posterior mitral valve leaflet with rudimentary papillary muscle heads and exceptionally short chordae directly implanting into the posterior annulus. The anterior leaflet was large and thickened with prolapse at all three scallops. We did not feel that a satisfactory result would be achieved with attempted repair, so we proceeded to replace the valve.
License terms Stuttgart · New York

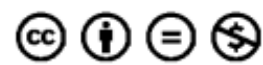

December 15, 2013 accepted after revision August 19, 2014 published online December 15, 2014
DOI http://dx.doi.org/ 10.1055/s-0034-1394104. ISSN 2194-7635. 


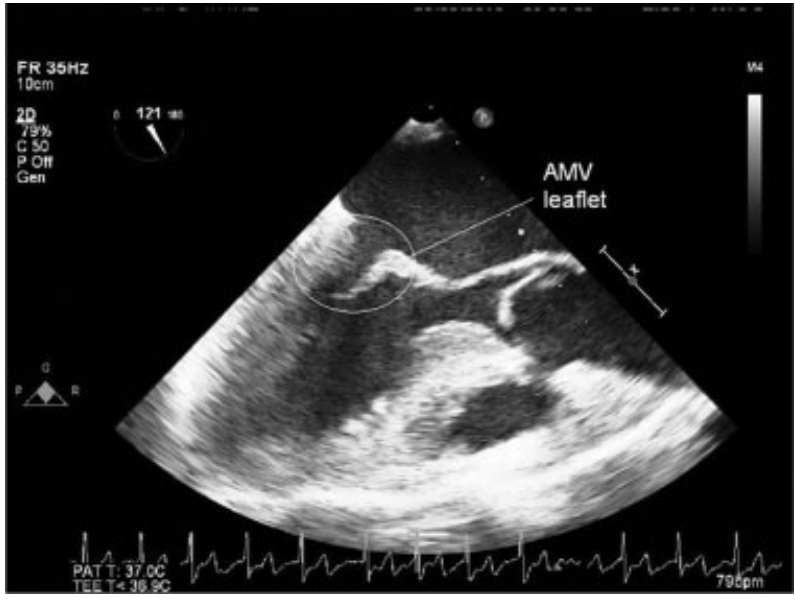

Fig. 1 Long axis transesophageal echocardiogram showing absence of a posterior valve leaflet. AMV, accessory mitral valve.

The anterior leaflet was excised ( - Fig. 2) and a 29-mm St Jude bileaflet mechanical valve was implanted at 90 degrees to the anatomical position using interrupted horizontal mattress sutures. The patient was discharged on her 5th postoperative day. Histology of the anterior valve leaflet showed hyaline and myxoid degeneration. On follow-up at 6 weeks, she met the criteria for NYHC 1 with a normal functioning mitral prosthesis.

\section{Discussion}

Classification of this type of mitral valve disease is not straightforward. Although a congenital defect exists, this patient's regurgitation was secondary to a prolapsed leaflet and histology showed degenerative changes. We would therefore classify this as Carpentier Type II. The prevalence has been reported by Bär et al (2009) as 1:8,800 in a prospective analysis of 26,484 preselected asymptomatic adult population. $^{3}$

Atresia of the posterior leaflet occurs during development of the left lateral endocardial cushion but the underlying process is not yet understood. It is associated with a compensatory elongation of the anterior leaflet. It has been proposed by Heper et al (2010) that leaflet growth is disrupted by a change in the

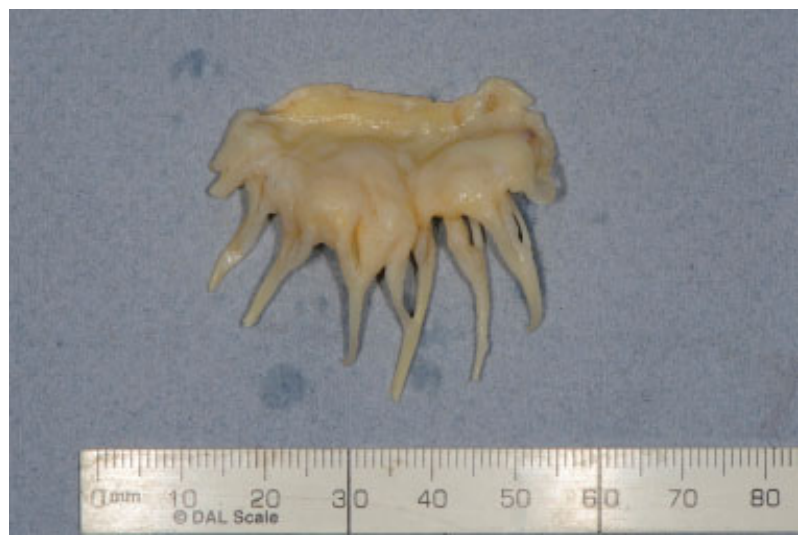

Fig. 2 Resected enlarged and thickened anterior valve leaflet. direction of blood flow through the atrioventricular orifice during diverticulation and undermining of the ventricular muscle from the ventricular wall. ${ }^{4}$ However, this is only speculation and there is no evidence to support this theory.

The prognosis for this condition without treatment has not been documented. It was initially believed that patients with this malformation did not survive beyond the neonatal period and reports of this condition in adults are few in number. ${ }^{2}$ Bär et al (2009) described this condition present in three adult patients. Two patients were found to have mild mitral regurgitation and one with moderate mitral regurgitation. In this series, mitral valve pathology was only identified as a result of selected screening in asymptomatic patients. ${ }^{3}$

The surgical management of an underdeveloped mitral valve leaflet in pediatric patients has been described. Kalangos et al reported the surgical management of a 10-year-old girl with annuloplasty. ${ }^{5}$ Their follow-up is limited to only 12 months. Caciolli et al similarly reported on a 14-year-old girl with similar pathology treated by annuloplasty. No longterm follow-up was documented. ${ }^{6}$ The oldest patient with an underdeveloped mitral valve leaflet receiving surgical intervention was aged 29. Stojanovic et al used pericardial patches to enlarge the posterior leaflet area, in addition to performing an annuloplasty. Their postoperative results were good but only a follow-up of 6 months is documented. ${ }^{7}$

Mitral valve repair is considered to be the optimal surgical treatment in adult patients with mitral valve regurgitation, especially for Carpentier Type II defects. When compared with replacement, there is a lower perioperative mortality and improved survival. Current guidelines on the management of heart valve disease emphasize that repair should be employed when possible; however, the durability of the repair and freedom from reoperation are not similar for all types of pathology. ${ }^{8}$ Thus, the optimal surgical treatment option in adults with underlying congenital defects is not so clear. There is very little evidence supporting the use of mitral valve repair in this situation due to the rarity of mitral valve leaflet atresia and thus long-term outcomes are not well described. In this case, mitral valve replacement was more appropriate to the individual needs of our patient. We decided to implant a mechanical valve as she was older than 65 years and her likelihood for reoperation would be minimized with replacement. In addition, we did not feel that ablation therapy for her atrial fibrillation would be successful as she had a dilated atrium on her preoperative echocardiogram, and so necessitating her continued need for warfarin anyway. And finally we did not feel a repair would yield satisfactory results. A satisfactory follow-up echocardiogram demonstrated normal functioning of her mitral prosthesis so she was discharged back to her general practitioner.

\section{References}

1 Kanagala P, Baker S, Green L, Houghton AR. Functionally uni-leaflet mitral valves in a family: a case series. Eur J Echocardiogr 2010; 11(7):E27

2 Ginghină C, Vlădaia A, Ghiorghiu I, Serban M, Popescu BA, Jurcuț R. Echocardiography in congenital mitral valve regurgitation-the 
36 Severe Mitral Regurgitation Joshi et al.

liaison between cardiologist and surgeon. J Med Life 2009;2(4): 407-413

3 Bär H, Siegmund A, Wolf D, Hardt S, Katus HA, Mereles D. Prevalence of asymptomatic mitral valve malformations. Clin Res Cardiol 2009;98(5):305-309

4 Heper G, Yetkin E, Senen K. Absence of posterior mitral leaflet with secundum atrial septal defect. Ann Thorac Surg 2010;90(6): 2055-2057

5 Kalangos A, Oberhansli I, Baldovinos A, Beghetti M, Friedli B, Faidutti B. Hypoplasia of the posterior leaflet as a rare cause of congenital mitral insufficiency. J Card Surg 1997;12(5):339-342
6 Caciolli S, Gelsomino S, Fradella G, Bevilacqua S, Favilli S, Gensini GF. Severe hypoplasia of the posterior mitral leaflet. Ann Thorac Surg 2008;86(6):1978-1979

7 Stojanovic I, Vukovic P, Boskovic S, Vuk LL, Korac NS. Repair of hammock mitral valve with hypoplastic posterior leaflet in an adult. J Heart Valve Dis 2010;19(6):803-805

8 Joint Task Force on the Management of Valvular Heart Disease of the European Society of Cardiology (ESC) European Association for Cardio-Thoracic Surgery (EACTS). Guidelines on the management of valvular heart disease (version 2012). Eur Heart J 2012;33(19): 2451-2496 